\title{
MicroRNAs: potential biomarkers for disease diagnosis
}

\author{
Li Xu ${ }^{\mathrm{a}}$, Xiuli Qi ${ }^{\mathrm{a},{ }^{*}, \text { Shengliang Duan }}{ }^{\mathrm{a}}$, Yumei Xie ${ }^{\mathrm{b}}$, Xinlei Ren ${ }^{\mathrm{a}}$, Gaoyun Chen ${ }^{\mathrm{a}}$, \\ Xiaocong Yang ${ }^{\mathrm{a}}$, Lili Han ${ }^{\mathrm{a}}$ and Qirui Dong ${ }^{\mathrm{a}}$ \\ ${ }^{a}$ Institute of Chemical Defence, Changping District, Beijing 102205, PR China \\ ${ }^{b}$ Academy of Equipment Command and Technology, Changping District, Beijing 102249, PR China
}

\begin{abstract}
MicroRNAs (miRNAs) are a group of endogenous noncoding small RNAs characterized by high conservation; furthermore, various studies have shown the capability of miRNAs to impact diseases. For example, a study shows that cellfree miRNAs are stable in bodily fluids, which gives circulating miRNAs the ability to be potential biomarkers for noninvasive diagnosis. Additionally, accumulating studies have supported that miRNAs can function as suppressor genes, again demonstrating their effect on disease. This review introduces this particular role of miRNAs as well as analyzes the prospect of miRNAs as biomarkers and the capacity for using miRNA-based resources to benefit mankind.
\end{abstract}

Keywords: MicroRNA, biomarker, disease diagnosis

\section{Introduction}

Many early diagnostic measures have been developed and are being increasingly used, such as endoscopic examinations and stool- and blood- based tests. Blood-based tests are becoming increasingly desirable because they are minimally invasive as well as have high levels of adherence in population-based screening. An amount of blood markers has been proposed and evaluated, including cytological, protein, mRNA, and DNA markers [1,2], but the diagnostic performance has mostly been insufficient as a primary tool. The miRNAs are a group of evolutionarily conserved, small, noncoding RNAs of 21 to $25 \mathrm{nt}$ and often negatively regulate gene expression at the post-transcriptional level by incomplete or complete complementary binding to target sequences with the 3' untranslated region of mRNAs [3]. Furthermore, there is increasing evidence that implicates miRNAs' involvement in a variety of biological processes, such as cell proliferation, differentiation, apoptosis, and tumorigenesis [4]. Accordingly, aberrant and/or absent expression of miRNAs is usually linked with pathophysiological disorders [5-7].

\footnotetext{
${ }^{*}$ Corresponding author: Xiuli Qi, Institute of Chemical Defence, Changping District, Beijing 102205, PR China. Tel.: +8615810032213; E-mail: qixiulilily@163.com.
}

0959-2989/14/\$27.50 @ 2014 - IOS Press and the authors. 


\section{Biological functions of miRNAs}

It has been proven that miRNAs are in plants, green algae, viruses, animals, and humans [8]. As lin4 and let-7 have been found to play important roles in the timing of $C$. elegans' larval development, much research has supported miRNAs as being associated with the other biological processes. With more than half of mammalian messages under selective pressure to maintain the pairing to miRNAs [9], it may prove, at least to some degree that miRNAs have influenced all the biological functions or processes in some cell types.

miRNAs are produced from the genomic DNAs that are transcribed by Pol II in the same way as mRNAs. Any hairpin secondary structures present in the RNAs are recognized and cleaved sequentially by the Drosha and Dicer enzymes. The mature miRNAs are the duplex of two RNA strands, on which there are approximately 22 nucleotides in length and two nucleotide 3 ' overhangs on each strand $[10,11]$. The target genes can be recognized by miRNAs with paring to the mRNAs of protein coding genes. Then, miRNAs direct their post-transcriptional repression via the degradation of mRNAs, the inhibition of protein translation, or a combination of the two [12,13]. One miRNA may modulate the expression of various proteins $[10,14]$.

Currently, there are 24,521 entries representing hairpin precursor miRNAs expressing 30,424 mature miRNA sequences in 206 species listed in the miRNA registry (Sanger miRBase release 20; http://www.mirbase.org/, June 2014). The registry shows that 2,652 mature human miRNAs are associated with lots of cellular pathophysiological pathways and are capable of significantly influencing the pathogenesis of some diseases. Table 1 shows some circulating miRNAs that are involved in human diseases.

Table 1

Diseases correlated with dysregulated circulating miRNA

\begin{tabular}{|c|c|c|c|c|c|}
\hline miRNAs & $\begin{array}{l}\text { Location on } \\
\text { Chromosome }\end{array}$ & $\begin{array}{l}\text { Target genes } \\
\text { proved }\end{array}$ & $\begin{array}{l}\text { Number of } \\
\text { researches }\end{array}$ & Tendency of expression level & Samples sizes \\
\hline $\operatorname{miR}-18 \mathrm{a}$ & $13 \mathrm{q} 31.3$ & BASP1 & $1[15]$ & Up in pancreatic cancer & 76 \\
\hline miR-20a & $13 q 31.3$ & SARA1 & $2[16]$ & Up in multiple myeloma & 40 \\
\hline \multirow[t]{8}{*}{$\operatorname{miR}-21$} & \multirow[t]{8}{*}{$17 q 23.2$} & \multirow{8}{*}{$\begin{array}{l}\text { PDCD4, PTEN, } \\
\text { SPRY1, SPRY2, } \\
\text { TPM1 }\end{array}$} & \multirow[t]{8}{*}{$7[15,17-22]$} & Up in $\mathrm{HCC}$ & 407 \\
\hline & & & & Up in ESCC & 70 \\
\hline & & & & Up in NSCLC & 93 \\
\hline & & & & Up in prostate cancer & 71 \\
\hline & & & & Up in pancreatic cancer & 60 \\
\hline & & & & $\mathrm{Up}$ in $\mathrm{GC}$ & 96 \\
\hline & & & & Up in pancreatic cancer & 85 \\
\hline & & & & $\mathrm{Up}$ in $\mathrm{CHC}$ & 81 \\
\hline miR-29a & $7 \mathrm{q} 32.3$ & MAP4K4 & $2[23-25]$ & Up in CRC & 159 \\
\hline
\end{tabular}




\begin{tabular}{|c|c|c|c|c|c|}
\hline miRNAs & $\begin{array}{l}\text { Location on } \\
\text { Chromosome }\end{array}$ & $\begin{array}{l}\text { Target genes } \\
\text { proved }\end{array}$ & $\begin{array}{l}\text { Number of } \\
\text { researches }\end{array}$ & Tendency of expression level & Samples sizes \\
\hline & & & & Up in active pulmonary tuberculosis & 127 \\
\hline \multirow[t]{6}{*}{ miR-92a } & \multirow[t]{6}{*}{$13 q 31.3$} & \multirow[t]{6}{*}{ ERß1, MUC16 } & \multirow{6}{*}{$\begin{array}{l}141 \\
{[24,26-31]}\end{array}$} & Up in CRC & 159 \\
\hline & & & & Up in CRC & 140 \\
\hline & & & & Down in $\mathrm{HCC}$ & 20 \\
\hline & & & & Down in acute leukemia & 77 \\
\hline & & & & Down in CRC & 102 \\
\hline & & & & Down in CAD & 53 \\
\hline miR-106b & $7 \mathrm{q} 22.1$ & $\begin{array}{l}\text { F3, IL-8, CTGF, } \\
\text { PAI-1 }\end{array}$ & $2[15]$ & $\mathrm{Up}$ in $\mathrm{GC}$ & 96 \\
\hline \multirow[t]{2}{*}{$\operatorname{miR}-133 a$} & \multirow[t]{2}{*}{$18 \mathrm{q} 11.2$} & \multirow{2}{*}{$\begin{array}{l}\text { SEC61B, FBN1, } \\
\text { TAGLN2, } \\
\text { GSTP1, ARPC5, } \\
\text { RFT1, C4orf34 }\end{array}$} & \multirow[t]{2}{*}{$3[28,32]$} & Up in CAD & 53 \\
\hline & & & & Up in AMI & 63 \\
\hline miR-143 & $5 q 32$ & $\begin{array}{l}\text { ERK5, } \\
\text { HNRPA2B }\end{array}$ & $2[33]$ & Up in enterovirus infection & 40 \\
\hline $\operatorname{miR}-145$ & $5 q 32.33$ & TIRAP & $1[28]$ & Down in CAD & 53 \\
\hline miR-146a & $5 q 33.3$ & $\begin{array}{l}\text { IRAK1, IRAK2, } \\
\text { TRAF6, RIG-1, } \\
\text { IRF-5, STAT-1, } \\
\text { PTC1, Numb }\end{array}$ & $1[28]$ & Up in CAD & 70 \\
\hline
\end{tabular}

Abbreviations: CRC, colorectal cancer; HCC, hepatocellular carcinoma; ESCC, oesophageal squamous cell carcinoma; NSCLC, non-small cell lung cancer; GC, gastric cancer; CAD, coronary artery disease; CHC, chronic hepatitis C virus infection; AMI, acute myocardial infarction; PTEN, phosphatase and tensin homolog; PDCD4, programmed cell death 4; TPM1, tropomyosin.

\section{3. miRNAs and disease diagnosis}

miRNAs modulate gene expression and are linked in the different physiological and pathological processes, including apoptosis, proliferation, development, and metabolism of glucose and lipids. Over time, there have been numerous studies conducted exploring the link between miRNAs' expression and disease; these studies have continued to be further enhanced and broadened [34-38].

\subsection{Cancer}

It has been proven that miRNAs are strongly dysregulated in cancer and show potential for cancer diagnosis, prognosis, and treatment [39]. Moreover, with the rapid development of miRNA microarrays, massive profiling studies in cancer patients have recently been made possible. 
Circulating miRNAs have been regarded as biomarkers for many cancers, including colorectal cancer, gastric cancer, and acute myeloblastic leukemia.

In addition, it has been demonstrated by abundant experimental evidence that miRNAs play roles as oncogenes or tumor suppressor genes, which suggests they have important effects on the development and progression of cancer. According to the expression profiles of human miRNAs, many miRNAs are expressed differentially in normal tissues and cancers and are deregulated in cancers. Over the past decades, many oncogenes and tumor suppressor genes have been recognized to regulate apoptosis, such as Bcl-2, p-53, and MYC [40-44]. This has improved the understanding of apoptotic signaling pathways and their dysregulation in cancer progression and treatment. Moreover, this class of miRNAs has revealed the apoptotic signaling pathways to be more complex and enigmatic than was previously appreciated [45]. Chim et al. reported that there are circulating miRNAs in serum/plasma, $[46,47]$ and they have found some tumor-derived miRNAs, such as miR-15b, miR-16, miR-17-92, miR-21, miR-24, miR-155, and let-7 miRNA in the plasma and sera of tumor-bearing patients $[48,49]$. Subsequently, more studies have shown that miRNAs may be used as potential biomarkers for different diseases, especially cancers [26,46,50]. Currently, the discovery and development of noninvasive tools for the diagnosis and management of cancer is a goal of cancer research. The application of miRNAs as the potential biomarkers will greatly decrease the worldwide health burden imposed by cancers [51].

\subsection{Cardiovascular disease}

Cardiovascular disease is one of the primary reasons for the rising rates of human morbidity and mortality worldwide. It increases the necessity for progressing novel diagnostics and therapies that are designed to detect cardiovascular diseases early. Current studies have shown not only the linkage between dysregulated miRNA expressions and diseased hearts but also the relevance of miRNA in the heart's growth, development, function, and stress responsiveness. Thus, it is very attractive to exploit miRNAs as diagnostic markers or to manipulate them to obtain therapeutic effects since they have very specific targets in a particular cellular pathway [52].

Willeit's research showed an important platelet contribution to the circulating miRNA pool and proposed miRNAs were responsive to antiplatelet therapy [53]. They found that the platelet-rich plasma exhibited significantly higher levels of miRNAs than both the serum and platelet-poor plasma. Conversely, the antiplatelet therapy significantly decreased miRNA levels. Willeit also evaluated 92 miRNAs from 377 miRNAs performed in the research by the dose-escalation method among healthy volunteers at 4 different time points. Furthermore, the results were validated by the individual TaqMan quantitative real-time PCR assay. It demonstrated that plasma levels of platelet miRNAs, including miR-223, miR-191, miR-126, and miR-150, were reduced by supplementary platelet inhibition. The work emphasized that antiplatelet therapy and the preparation of blood samples could be confusing factors in the case-control research that link miRNAs to cardiovascular diseases.

\subsection{Diabetes}

Until now, sensitive methods for the identification of $\beta$-cell death and the early detection of diabetes have been absent. Erener et al. [54] studied miR-375 levels, an islet enriched miRNA, by quantitative RT-PCR in order to verify whether miR-375 is a possible biomarker in blood for identifying $\beta$-cell death and predicting diabetes in mice. Moreover, they found the levels of circulating miR-375 of the cytokine- and streptozotocin-induced islets were significantly enhanced, whereas the miR-375 levels 
were decreased by cell death inhibitors. The results suggested that circulating miR-375 is possibly regarded as the biomarker of $\beta$-cell death and a predictor of diabetes.

\subsection{Occupational disease}

Exposure to asbestos is the predominant cause of pleural mesothelioma (PM). PM is a tumor that is difficult to diagnose. Thirteen novel asbestos-related miRNAs have been revealed (over-expressed: miR-148b, miR-374a, miR-24-1*, Let-7d, Let-7e, miR-199b-5p, miR-331-3p, and miR-96 and underexpressed: miR-939, miR-671-5p, miR-605, miR-1224-5p and miR-202) [55].

Inorganic Arsenic (iAs) is a metalloid widely diffused in all environmental matrices. The International Agency for Research on Cancer classifies iAs as a Group 1 carcinogen. Present studies have evaluated the influence of iAs exposure on the expression of total miRNA in Jurkat cells. Treated cells showed a reproducible increase in the expression levels of three miRNAs: miR-663, miR-222, and miR-638. The study supports the importance of continuing the investigation of the possible application of some miRNAs as biomarkers in environmental and occupational iAs exposure [56].

\subsection{Acute rejection of organ transplant}

Recently, a few markers have been applicable for the clinical diagnosis of the acute rejection (AR) of an organ transplant. Attempting to confirm whether the plasma miRNAs can be potential biomarkers for $\mathrm{AR}, \mathrm{Hu}$ et al. used the rat orthotopic liver transplantation model and microarrays [57] to distinguish the variation from the miRNAs fingerprint and levels in plasma and grafts derived from the AR rats and the control, respectively. They found that three plasma miRNAs, miR-122, miR-192, and miR-146a, were notably up-regulated when AR was conducted, and the increase could be inhibited by immunosuppression. They also demonstrated the presence of miR-122 and miR-192 rather than miR-146a in the liver-injury rat model. The succeeding study showed that miR-146a was up-regulated sixfold in microvesicle in AR plasma. However, miR-122 and miR-192 indicated little specific change. The studies provided the total spectrum of plasma miRNAs in AR rats and also suggested that miR-122 and miR-192 were linked with liver injury, as well as miR-146a possibly being related to cellular rejection. Moreover, many current studies have proposed the possibility of miRNA serving as biomarkers for evaluating the renal allograft status for kidney transplantation $[58,59]$.

HDmiRs can be a promising biomarker for evaluating the allograft status after a liver transplant. Recently, HDmiR miR-122 has been found in serum and the miR-122 level increased significantly if the patients suffered hepatocyte injuries by viral, alcoholic, or chemical-related hepatotoxicity $[60,61]$. Further study showed the levels of both serum and plasma miR-122 correlated closely with the aminotransferases and liver histology of the patients. Furthermore, Waqar et al. demonstrated that the expression of miR-122 and miR-148a in liver tissue changed significantly with prolonged graft warm ischemia times during ischemia/reperfusion injury and acute rejection [62].

\subsection{Osteoarthritis}

Osteoarthritis (OA) is currently the most prevalent degenerative joint disease, characterized by injury of the articular cartilage due to environmental, mechanical, or genetic factors. The genetics of OA are complicated and are not wholly understood. Recent studies, however, have shown the significance of miRNAs in cartilage functions [63]. Silvia et al. has conducted research on identifying 
and characterizing the expression profile of miRNAs in normal and OA chondrocytes. They aimed to analyze and determine the role of the 723 miRNAs in OA, of which seven miRNAs showed a statistically significant differential expression. Moreover, they found that from among these seven human miRNAs, hsa-miR-483-5p was upregulated in OA chondrocytes, and the other six miRNAs, including hsa-miR-149*, hsa-miR-582-3p, hsa-miR-1227, hsa-miR-634, hsa-miR-576-5p, and hsamiR-641 were upregulated in normal chondrocytes. The profiling results were affirmed by the detection of the specific miRNAs by qPCR. The possible role of the detected miRNAs in OA pathology was revealed and supported by the potential miRNA target predictions and the signaling cascades altered by the differentially expressed miRNAs.

Recently, Jones et al. found that miR-149* was down-regulated in OA chondrocyte micropellets [64]. The expression profiles of 157 human miRNAs have been studied and identified. Of those studied, 17 miRNAs were shown to be differentially expressed in human OA in comparison to normal cartilage. In the study, hsa-miR-140 showed a tendency to be downregulated in OA, and hsa-miR-146 was upregulated in this pathology. These findings stood in opposition to previous reports' results $[65,66]$.

\section{Conclusion}

Over time, as shown in Table 1 and Table 2, there have been numerous studies conducted exploring the link between miRNAs'expression and disease; these studies have continued to be further enhanced and broadened.

We should pay more attention to identifying the classifications and levels of miRNAs characterized in both low and high risk populations, and we should develop more capable and regulatory methods and databases for screening the useful miRNAs markers for early disease diagnosis, prognosis, prevention, and prediction of therapeutic responses to diseases from the wealth of information available from miRNAs (see in Figure 1).

Table 2

miRNAs dysregulated in disease

\begin{tabular}{|c|c|c|c|}
\hline \multicolumn{2}{|l|}{ Diseases } & $\begin{array}{l}\text { the correlated miRNAs proven } \\
\text { (' } \uparrow \text { ', upregulate; ' } \downarrow \text { ', downregulate) }\end{array}$ & reference \\
\hline \multicolumn{2}{|l|}{ cancers } & $\begin{array}{l}\operatorname{miR}-15 b(\uparrow), \operatorname{miR}-16(\uparrow), \operatorname{miR}-17-92(\uparrow), \operatorname{miR}-21(\uparrow), \\
\operatorname{miR}-24(\uparrow), \operatorname{miR}-155(\uparrow), \text { let-7 miRNA }(\downarrow)\end{array}$ & {$[47-51]$} \\
\hline \multicolumn{2}{|c|}{ Cardiovascular disease } & $\operatorname{miR}-223(\uparrow), \operatorname{miR}-191(\uparrow), \operatorname{miR}-126(\uparrow), \operatorname{miR}-150(\uparrow)$ & {$[52,53]$} \\
\hline \multicolumn{2}{|l|}{ Diabetes } & $\operatorname{miR}-375(\uparrow)$ & {$[54]$} \\
\hline \multirow[t]{2}{*}{$\begin{array}{l}\text { Occupational } \\
\text { Disease }\end{array}$} & Asbestos-related PM & $\begin{array}{l}\operatorname{miR}-148 \mathrm{~b}(\uparrow), \operatorname{miR}-374 \mathrm{a}(\uparrow), \operatorname{miR}-24-1(\uparrow), \text { Let-7d }(\uparrow), \\
\text { Let-7e }(\uparrow), \operatorname{miR}-199 \mathrm{~b}-5 \mathrm{p}(\uparrow), \operatorname{miR}-331-3 \mathrm{p}(\uparrow), \operatorname{miR}-96(\uparrow), \operatorname{miR}- \\
939(\downarrow), \operatorname{miR}-671-5 \mathrm{p}(\downarrow), \operatorname{miR}-605(\downarrow), \operatorname{miR}-1224-5 \mathrm{p}(\downarrow), \\
202(\downarrow)\end{array}$ & {$[55]$} \\
\hline & $\begin{array}{l}\text { Exposed to Inorganic } \\
\text { Arsenic }\end{array}$ & $\operatorname{miR}-663(\uparrow), \operatorname{miR}-222(\uparrow), \operatorname{miR}-638(\uparrow)$ & {$[56]$} \\
\hline \multicolumn{2}{|c|}{ Acute Rejection of Organ Transplant } & $\operatorname{miR}-122(\uparrow), \operatorname{miR}-192(\uparrow), \operatorname{miR}-146 a(\uparrow), \operatorname{miR} 148 \mathrm{a}(\uparrow)$ & {$[57-62]$} \\
\hline \multicolumn{2}{|l|}{ Osteoarthritis } & hsa-miR-483-5p( $\uparrow), \operatorname{miR}-149(\downarrow)$ & {$[63,64]$} \\
\hline
\end{tabular}




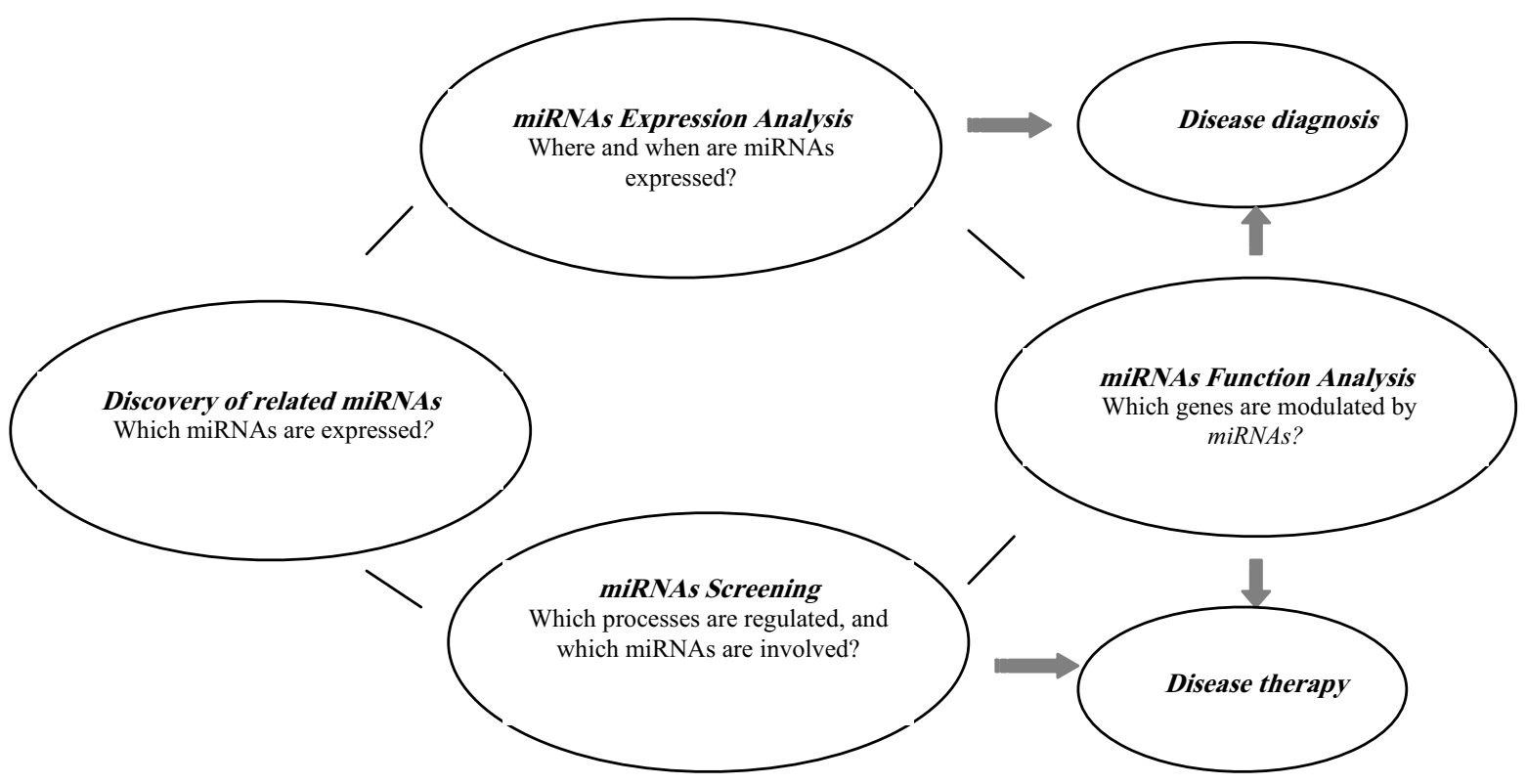

Fig. 1. The general strategy of research conducted on miRNAs biomarkers.

\section{References}

[1] S. Hundt, U. Haug and H. Brenner, Blood markers for early detection of colorectal cancer: a systematic review, Cancer Epidemiol Biomarkers Prev. 16 (2007), 1935-1953.

[2] S. Tao, S. Hundt, U. Haug and H Brenner, Sensitivity estimates of blood-based tests for colorectal cancer detection: impact of overrepresentation of advanced stage disease, Am. J. Gastroenterol. 106 (2011), 242-253.

[3] D.H. Chitwood and M.C. Timmermans, Target mimics modulates miRNAs, Nat Genet 39 (2007), 935-936.

[4] V. Ambros, The functions of animal microRNAs, Nature 431 (2004), 350-355.

[5] C.Z. Chen, L. Li, H.F. Lodish et al, MicroRNAs modulate hematopoietic lineage differentiation, Science 303 (2004), 83-86.

[6] C. Roldo, E. Missiaglia, J.P. Hagan et al, MicroRNA expression abnormalities in pancreatic endocrine and acinar tumors are associated with distinctive pathologic features and clinical behavior, J. Clin. Oncol. 24 (2006), 4677-4684.

[7] J.J. Zhao, Y.J. Hua, D.G. Sun et al, Genome-wide microRNA profiling in human fetal nervous tissues by oligonucleotide microarray, Childs. Nerv. Syst. 22 (2006), 1419-1425.

[8] S. Griffiths-Jones, H.K. Saini, S.V. Dongen and A.J. Enright, MiR Base: tools for microRNA genomics, Nucleic Acids Res. 36 (2008), D154-D158.

[9] R.C. Friedman, K.K. Farh, C.B. Burge and D.P. Bartel, Most mammalian mRNAs are conserved targets of microRNAs, Genome Res. 27 (2008), 92-105.

[10] D.P. Bartel, MicroRNAs: genomics, biogenesis, mechanism, and function, Cell 116 (2004), 281-297.

[11] G.J. Hannon, RNA interference, Nature 418 (2002), 244-251.

[12] R.C. Lee, R.L. Feinbaum and V. Ambros, The C. elegan's heterochronic gene lin-4 encodes small RNAs with antisense complementarity to lin-14, Cell 75 (1993), 843-854.

[13] D.P. Bartel, MicroRNAs: target reconization and regulatory function, Cell 136 (2009), 215-233.

[14] P.D. Zamore and B. Haley, Ribo-gnome: the big world of small RNAs, Science 309 (2005), 1519-1524.

[15] S. Komatsu, D. Ichikawa, H. Takeshita, M. Tsujiura, R. Morimura et al., Circulating microRNAs in plasma of patients with oesophageal squamous cell carcinoma, Br. J. Cancer 105 (2011), 104-115.

[16] M.M. Georgescu, PTEN tumor suppressor network in PI3K-Akt pathway control, Genes Cancer 1 (2010), 1170-1177.

[17] S. Ali, K. Almhanna, W. Chen, P.A. Philip and F.H. Sarkar, Differentially expressed miRNAs in the plasma may provide a molecular signature for aggressive pancreatic cancer, Am. J. Transl. Res. 3 (2010), 28-47. 
[18] V. Bihrer, O. Waidmann, M. Friedrich-Rust et al, Serum microRNA-21 as marker for neucroinflammation in hepatitis C patients with and without hepatocellular carcinoma, PLOS One 6 (2011), e26971-1-e26971-7.

[19] M. Tsujiura, D. Ichikawa, S. Komatsu et al, Circulating microRNAs in plasma of patients with gastric cancers, Br. J. Cancer 102 (2010), 1174-1183.

[20] G.K. Wang, J.Q. Zhu, J.T. Zhang et al., Circulating microRNA: a novel potential biomarker for early diagnosis of acute myocardial infarction in humans, Eur. Heart J. 31 (2010), 659-666.

[21] J. Wei, W. Gao, C.J. Zhu et al., Identification of plasma microRNA-21 as a biomarker for early detection and chemosensitivity of nonsmall cell lung cancer, Chin. J. Cancer 30 (2011), 407-414.

[22] F. Yaman Agaoglu, M. Kovancilar, Y. Dizdar et al., Investigation of miR-21, miR-141, and miR-221 in blood circulation of patients with prostate cancer, Tumour Biol. 32 (2011), 583-588.

[23] X.Y. Luo, S. Christian, B. Barbara and B. Hermann, Identification and evaluation of plasma microRNAs for early detection of colorectal cancer, PLoS One 8 (2013), e62880-1-e62880-9.

[24] Z. Huang, D. Huang, S. Ni et al., Plasma microRNAs are promising novel biomarkers for early detection of colorectal cancer, Int. J. Cancer 127 (2010), 118-126.

[25] Y. Fu, Z. Yi, X. Wu, J. Li and F. Xu, Circulating microRNAs in patients with active pulmonary tuberculosis, J. Clin. Microbiol. 49 (2011), 4246-4251.

[26] E.K. Ng, W.W. Chong, H. Jin, E.K. Lam et al., Differential expression of microRNAs in plasma of patients with colorectal cancer: a potential marker for colorectal cancer screening, Gut 58 (2009), 1375-1381.

[27] H. Cheng, L. Zhang, D.E. Cogdell et al., Circulating plasma MiR-141 is a novel biomarker for metastatic colon cancer and predicts poor prognosis, PLoS One 6 (2011), e17745-1-e17745-8.

[28] S. Fichtlscherer, S. De Rosa, H. Fox et al., Circulating microRNAs in patients with coronary artery disease, Circ. Res. 107 (2010), 677-684.

[29] R. Morimura, S. Komatsu, D. Ichikawa et al., Novel diagnostic value of circulating miR-18a in plasma of patients with pancreatic cancer, Br. J. Cancer 105 (2011), 1733-1740.

[30] M. Shigoka, A. Tsuchida, T. Matsudo et al., Deregulation of miR-92a expression is implicated in hepatocellular carcinoma development, Pathol Int. 60 (2010), 351-357.

[31] S. Tao, U. Haug, K. Kuhn and H. Brenner, Comparison and combination of blood-based inflammatory markers with faecal occult blood tests for noninvasive colorectal cancer screening, Br. J. Cancer 106 (2012), 1424-1430.

[32] M. Tanaka, K. Oikawa, M. Takanashi et al., Downregulation of miR-92 in human plasma is a novel marker for acute leukemia patients, PLoS One 4 (2009), e5532-1-e5532-5.

[33] L. Cui, Y. Qi, H. Li et al., Serum microRNA expression profile distinguishes enterovirus 71 and coxsackievirus 16 infections in patients with hand-foot-and-mouth disease, PLoS One 6 (2011), e27071-1-e27071-6.

[34] M. Osaki, F. Takeshita and T. Ochiya, MicroRNAs as biomarkers and therapeutic drugs in human cancer, Biomarkers 13 (2008), 658-670.

[35] C.M. Croce, Causes and consequences of microRNA dysregulation in cancer, Nat. Rev. Genet. 10 (2009), 704-714.

[36] J. Lu, G. Getz, E.A. Miska et al., MicroRNA expression profiles classify human cancers, Nature 435 (2005), 834-838.

[37] A. Esquela-Kerscher and F.J. Slack, Oncomirs - microRNAs with a role in cancer, Nat. Rev. Cancer 6 (2006), $259-269$.

[38] H. Osada and T. Takahashi, MicroRNAs in biological processes and carcinogenesis, Carcinogenesis 28 (2007), 2-12.

[39] A. Lujambio and S.W. Lowe, The microcosmos of cancer, Nature 482 (2012), 347-355.

[40] S. Erster, M. Mihara, R.H. Kim et al., In vivo mitochondrial p53 translocation triggers a rapid first wave of cell death in response to DNA that can precede p53 target gene activation, Mol. Cell Biol. 24 (2004), 6728-6741.

[41] D.R. Green and G. Kroemer, Cytoplastmic functions of the tumor suppressor p53, Nature 458 (2009), 1127-1130.

[42] B. Hoffman and D.A. Liebermann, Apoptotic signaling by c-MYC, Oncogene 27 (2008), 6462-6472.

[43] J. Klefstrom, E.W. Verschuren and G. Evan, c-MYC augments the apoptotic activity of cytosolic death receptor signalling proteins by engaging the mitochondrial apoptotic pathway, J. Biol. Chem. 277 (2002), 43224-43232.

[44] P. S elengaris, M. Khan and G.I. Evan, Suppression of Mic-induced apoptosis in beta cells exposes multiple oncogenic properties of Myc and triggers carcinogenic progression, Cell 109 (2002), 321-334.

[45] T.G. Cotter, Apoptosis and cancer: the genesis of research field, Nat. Rev. Cancer 9 (2009), 501-507.

[46] S.S. Chim, T.K. Shing, E.C. Hung et al., Detection and characterization of placental microRNAs in maternal plasma, Clin Chem. 54 (2008), 482-490. R. Etzioni, N. Urban, S. Ramsey et al., The case for early detection, Nat. Rev. Cancer 3 (2003), 243-252.

[47] S. Gilad, E. Meiri, Y. Yogev et al., Serum microRNAs are promising novel biomarkers, PLoS One 3 (2008), e3148-1e3148-7.

[48] C.H. Lawrie, S. Gal, H.M. Dunlop et al., Detection of elevated levels of tumour-associated microRNAs in serum of patients with diffuse large B-cell lymphoma, Br. J. Haematol. 141 (2008), 672-675. 
[49] P.S. Mitchell, R.K. Parkin, E.M. Kroh et al., Circulating microRNAs as stable blood-based markers for cancer detection, Proc. Natl. Acad. Sci. USA 105 (2008), 10513-10518.

[50] X. Chen, Y. Ba, L. Ma et al., Characterization of microRNAs in serum: a novel class of biomarkers for diagnosis of cancer and other diseases, Cell Res. 18 (2008), 997-1006.

[51] R. Etzioni, N. Urban, S. Ramsey et al., The case for early detection, Nat. Rev. Cancer 3 (2003), 243-252.

[52] R.V. Kartha and S. Subramanian, MicroRNAs in cardiovascular diseases: biology and potential clinical applications, J. Cardiovasc. Transl. Res. 3 (2010), 256-270.

[53] P. Willeit, A. Zampetaki, K. Dudek et al., Circulating microRNAs as novel biomarkers for platelet activation, Circ. Res. 112 (2013), 595-600.

[54] S. Erener, M. Mojibian, J.K. Fox et al., Circulating miR-375 as a biomarker of $\beta$-cell death and diabetes in mice, Endocrinology 154 (2013), 603-608.

[55] E. Sturchio, A. Amadori, J. Businaro et al., Possible use of microRNAs as biomarkers for monitoring of workers exposed to asbestos, G Ital. Med. Lav. Ergon. 3 (2012), 571-573.

[56] E. Sturchio, T. Colombo, N. Carucci et al., Molecular biomarkers in workers and population exposed to inorganic arsenic: preliminary study in vitro, G Ital. Med. Lav. Ergon. 3 (2012): 678-681.

[57] J. Hu, Z. Wang, C.J. Tan et al., Plasma microRNA, a potential biomarker for acute rejection after liver transplantation, Transplantation 95 ( 2013), 991-999

[58] V. Bihrer, M. Friedrich-Rust, B. Kronenberger et al., Serum miR-122 as a biomarker of neuroinflammation in patients with chronic hepatitis C virus infection, Am. J. Gastroenterol. 106 (2011), 1663-1669.

[59] B. Li, C. Hartono, R. Ding et al., Noninvasive diagnosis of renal-allograft rejection by measurement of messenger RNA for perforin and granzyme B in urine, N Engl. J. Med. 344 (2001), 947-954.

[60] A. Bonauer, G. Carmona, M. Iwasaki et al., MicroRNA-92a controls angiogenesis and functional recovery of ischemic tissues in mice, Science 324 (2009), 1710-1713.

[61] Y. Zhang, Y. Jia, R. Zheng et al., Plasma microRNA-122 as a biomarker for viral-, alcohol-, and chemical-related hepatic diseases, Clin. Chem. 56 (2010), 1830-1838.

[62] A.A. Bravo, S.G. Sheth and S. Chopra, Liver biopsy, N. Engl. J. Med. 344 (2001), 495-500.

[63] R. Waqar, R. Farid, Qiuwei Pan et al., Hepatocyte-derived microRNAs as serum biomarkers of hepatic injury and rejection after liver transplantation, Liver Transplantation 18 (2012), 290-297.

[64] D.P. Silvia, C. Claudia, M.L. Emma et al., Characterization of microRNA expression profiles in normal and osteoarthritic human chondrocytes, BMC Musculoskelet Disord. 13 (2012), 144-156.

[65] S.W. Jones, G. Watkins, N. Le Good et al., The identification of differentially expressed microRNA in osteoarthritic tissue that modulate the production of TNF-alpha and MMP13, Osteoarthr Cartilage 17 (2009), 464-472.

[66] D. Iliopoulos, K.N. Malizos, P. Oikonomou and A. Tsezou, Integrative microRNA and proteomic approaches identify novel osteoarthritis genes and their collaborative metabolic and inflammatory networks, PLoS One 3 (2008), e3740-1e3740-10. 